\title{
Avaliação da atenção concentrada no contexto do trânsito
}

\author{
Thatiana Helena de Lima - Universidade São Francisco, Itatiba, Brasil
}

Rueda, F. J. M., \& Sisto, F. F. (2009). Teste de Atenção Concentrada (TEACO- FF). $1^{\text {a }}$ edição. São Paulo: Casa do Psicólogo. 112 p.

Diante do grande número de acidentes de trânsito que acontecem no país, acredita-se na necessidade de estudos que demonstrem quais características estão relacionadas com o ato de dirigir. Nesse sentido, foram realizadas algumas pesquisas que mostraram que a atenção concentrada seria um atributo importante para aquelas pessoas que desejam dirigir veículos automotores. Dessa forma, foi elaborado o Teste de Atenção Concentrada (TEACO-FF), que tem por objetivo avaliar a capacidade de uma pessoa em selecionar apenas uma fonte de informação diante de vários estímulos distratores num tempo pre determinado.

Os autores do teste apontam a necessidade de definir o que é entendido por trânsito, tendo em vista que esse termo apresenta várias conceituações. Dessa forma, na fundamentação teórica do teste são apresentadas diversas definições que dizem respeito ao significado de trânsito, que é a utilização de vias por pessoas, veículos e animais, isolados ou em grupos, conduzidos ou não, para fins de circulação, parada, estacionamento e operação de carga ou descarga. Refere-se, também, à estrutura do trânsito, que é constituída de subsistemas, em que os principais são o homem, o veículo e a via. Pontuam o fato de, ao se falar em trânsito, pensar-se no ato de dirigir, sendo isso comum à maioria das pessoas. Segundo os autores, no processo cognitivo das pessoas ao dirigir um veículo, muitas informações seriam reunidas e avaliadas num período curto de tempo. Assim, dirigir um veículo seria trabalho para especialistas e necessitaria de uma preparação especial.

Considerando que a atenção é o fenômeno pelo qual o ser humano processa ativamente uma quantidade limitada de informações do enorme montante disponível por meio dos órgãos do sentido, de memórias armazenadas e de outros processos cognitivos, de acordo com os autores, a mesma pode ser dividida em dois componentes: a atenção explícita, que se refere aos processos conscientes, e a atenção implícita, que seriam os processos não conscientes. De acordo com as

\footnotetext{
${ }^{1}$ E-mail: thatyhl@hotmail.com
}

pesquisas científicas realizadas tendo como foco esse construto, a melhor forma de se avaliar a atenção seria visualmente.

Pela dificuldade de se encontrarem pesquisas nacionais que relacionem a avaliação da atenção no contexto do trânsito, no manual do teste são apresentadas diversas pesquisas estrangeiras encontradas na literatura. Ainda, um dos motivos principais para realizar a construção do instrumento foi a escassez de medidas que possuam evidências de validade e coeficientes de precisão de acordo com o padrão de qualidade exigido pelo Conselho Federal de Psicologia (CFP), o que compromete o aumento de pesquisas nesse campo.

O instrumento é composto por um Manual, Folha de Resposta e Crivo de Correção, o primeiro contendo a fundamentação teórica, estudos psicométricos de validade e precisão, normas de aplicação, correção e interpretação, com tabelas normativas para a transformação do escore bruto em percentil, finalizando com exemplos de correção, pontuação e interpretação de protocolos. $\mathrm{Na}$ folha de resposta, há 500 estímulos distribuídos em 20 colunas com 25 estímulos cada. Do total, são 180 estímulos-alvo, cada coluna tendo nove estímulos-alvo e 16 estímulos distratores. No topo da folha de resposta encontra-se o estímulo-alvo, para que a pessoa possa visualizá-lo enquanto realiza o teste. A localização dos símbolos foi sorteada de modo que não houvesse repetições. $O$ tempo de aplicação é de 4 minutos. Já para a correção, há o crivo de pontuação no qual se encontram espaços que indicam as figuras que deveriam ter sido assinaladas pelo examinando. Depois devem ser contados os erros, que são as figuras marcadas que estão fora dos espaços em branco do crivo de correção. Por fim, devem ser contadas as omissões, que são as figuras que deveriam ser marcadas e não o foram, considerando até a última figura marcada. Dessa forma, soma-se o número de erros e de omissões e subtrai-se dos acertos. Após, deve-se procurar o percentil na tabela normativa mais apropriada para o examinando.

A fim de analisar as características psicométricas do instrumento, os autores o 
aplicaram em uma amostra de 1.058 sujeitos, dos estados da Bahia e de Sergipe, tendo os 367 sujeitos da Bahia passado pelo processo de avaliação psicológica pericial para obtenção, renovação ou mudança de categoria da Carteira Nacional de Habilitação. Dos participantes de Sergipe, 184 eram candidatos à obtenção da $\mathrm{CNH}$ que passaram pela avaliação psicológica pericial e 507 eram estudantes universitários de vários cursos das áreas de humanas, biológicas e exatas de uma instituição particular, a maioria já possuindo $\mathrm{CNH}$. A escolaridade variou desde ensino fundamental incompleto até a pósgraduação, e com profissões diferentes. A idade mínima foi de 18 anos e a máxima de 61 anos, com média de 25,21 anos. Quanto ao sexo, 512 eram homens e 546 mulheres.

No que diz respeito à validade, foram realizados estudos de evidência de validade de construto pela diferenciação das idades; validade relativa a estrutura interna; validade de critério, em relação à escolaridade, em relação ao tipo de avaliação psicológica pericial, em relação à categoria da $\mathrm{CNH}$, e pelo fato de exercer ou não atividade remunerada. Foram também realizados estudos de validade convergente e concorrente e análise dos itens pelo modelo de Rasch.

No que se refere à precisão, foi estudada em relação às faixas etárias e sexo por meio do coeficiente alfa de Cronbach, as duas metades Spearman-Brown e Guttman e pelo modelo Rasch. Os índices, que foram considerados excelentes, variaram de 0,90 a 0,97 pelo coeficiente de consistência interna (alfa de Cronbach) e de 0,90 a
0,98 pelo método das metades Spearman-Brown e Guttman. No modelo Rasch os coeficientes variaram de 0,89 a 0,99 .

Para a correção do TEACO-FF, inicialmente aplica-se o crivo de pontuação, no qual encontram-se espaços que indicam as figuras que deveriam ter sido assinaladas pelo examinando. Depois devem ser contados os erros, as figuras marcadas que estão fora dos espaços em branco do crivo de correção. Por fim, devem ser contadas as omissões, que são as figuras que deveriam ser marcadas e não o foram, considerando até a última figura marcada. Dessa forma, soma-se o número de erros e de omissões e subtrai-se dos acertos. Posteriormente deve-se procurar o percentil na tabela normativa mais apropriada para o examinando.

É grande a dificuldade de se encontrarem instrumentos com boas qualidades psicométricas e dados de normatização para a população brasileira, principalmente no que diz respeito ao trânsito, que tem sido mais estudado nos últimos anos, mas ainda carece de pesquisas e do desenvolvimento de instrumentos que forneçam resultados confiáveis. Dessa forma, o TEACO-FF vem de forma a preencher um espaço nessa lacuna existente, visto que o material que o compõe possui linguagem clara e compreensível aos profissionais da área. Destinado aos psicólogos que trabalham com avaliação psicológica no contexto do trânsito, fornece uma medida confiável, capaz de medir aquilo que propõe, gerando confiabilidade em seus resultados.

Sobre a autora:

Thatiana Helena de Lima é psicóloga e mestranda em Psicologia pelo Programa de Pós-Graduação Stricto Sensu da Universidade São Francisco. 